\title{
Editorial
}

\section{Clinical research on children}

The Society for the Study of Medical Ethics has established an interdisciplinary working party to study the ethics of clinical research investigations on children. Why should such an enterprise be considered necessary? What are the main problems to be resolved?

Perhaps the most appealing justification, so far as many doctors are concerned is that although there exist several authoritative guidelines for such research these actually conflict in their advice, especially concerning what is probably the most contentious aspect of the problem, clinical research which is not designed to be of direct benefit to the subject (non-therapeutic research or NTR).

The Helsinki Declaration, reviewed and revised by the World Medical Association as recently as I975 states unequivocally that for such research 'the subjects should be volunteers'. Moreover, a 'doctor can combine medical research with professional care, the objective being the acquisition of new medical knowledge, only to the extent that medical research is justified by its potential diagnostic or therapeutic value for the patient'; and it twice states that 'in research on man the interest of science and society should never take precedence over considerations related to the wellbeing of the subject' (I). The earlier Nuremberg Code also explicitly states that for all human experimentation 'the voluntary consent of the human subject is absolutely essential' and adds that this entails legal capacity to give consent, free power of choice, and sufficient knowledge and comprehension 'to make an understanding and enlightened decision' (2).

The Medical Research Council in its 1963 statement on 'Responsibility in investigation on human subjects' was equally explicit: 'investigations that are of no direct benefit to the individual require therefore that his true consent to them shall be explicitly obtained'. It advised (on the basis of eminent legal counsel's opinion) that 'when the subject is below the age of 12 years information requiring the performance of any procedure involving his body would need to be obtained incidentally to and without altering the nature of a procedure intended for his individual benefit'; and it states: 'in the strict view of the law parents and guardians of minors cannot give consent on their behalf to any procedures which are of no particular benefit to them and which may carry some risk of harm' (3).

All three of these guides rule out much if not all NTR on children. The Royal College of Physicians' 1973 report on 'the supervision of the ethics of clinical research investigations in institutions' marked a change in attitude when it stated: 'if advances in medical treatment are to continue so must clinical research investigation. It is in this light therefore that it is recommended that clinical research investigation of children or mentally handicapped adults which is not of direct benefit to the patient should be conducted': but it added that such NTR was permissible 'only when the procedures entail negligible risk or discomfort and subject to the provisions of any common and statute law prevailing at the time. The parent or guardian should be consulted and his agreement recorded' (4).

In 1975 the Department of Health and Social Security somewhat equivocally circulated both the MRC and the RCP views without additional comment (5): the then Chief Medical Officer wrote elsewhere that it was not legitimate to perform any experiment on a child that was not in the child's interests (6).

The British Medical Association's Handbook of Medical Ethics for 1981 (7), although it states explicitly that it is unethical to carry out NTR on prisoners makes no such differentiation between therapeutic and non-therapeutic research on children. It suggests, though does not state, that provided parental consent is obtained NTR may be performed on children; but it also endorses the Helsinki Declaration, and explicitly states that 'the subject's interests must come first'. Interestingly, in I981 the Handbook drops advice given in the 1980 edition that 'the risks must be properly assessed and weighed against the benefits' and also the words: 'the investigators should be prepared to defend and justify the ethics of the research to colleagues and to the local ethical committee'.

In 1980 the British Paediatric Association published 'guidelines to aid ethical committees considering research involving children' (8) in which the general trend to loosen restrictions on NTR on children seems to have accelerated markedly. Thus the guidelines state explicitly that more than negligible risk in such experiments may be justifiable provided the anticipated benefits are 
sufficiently great; and their definition of 'negligible' allows what would widely be considered quite substantial risks to be classified as 'negligible'. Thus, having classified risk into three categories, negligible, minimal and more than minimal, and having asserted that no ethical committee would countenance the risk of serious harm in any research procedure, the guidelines state: 'During the course of an abdominal operation a renal biopsy might be taken for research purposes. The risk here would be judged more than minimal and the benefit would have to be very large to justify it. But suppose the research aimed to resolve the problem of rejection of transplanted kidneys with resulting lifesaving consequences both for children and adults with renal failure, this might be considered a benefit of sufficient magnitude to justify the risk'. The guidelines give similar risk benefit analyses to justify nontherapeutic, possibly repeated, blood sampling.

At first sight this may seem inconsistent with the earlier disclaimer that no ethical committee would accept a risk of possible 'serious harm' to research subjects; after all renal biopsies and even repeated venepunctures (let alone arterial punctures for blood gas estimates) may, rarely, result in appreciable morbidity and there is even a risk, statistically of very low probability but present nonetheless, of a patient dying because of such investigations. The BPA is not however inconsistent for it defines 'negligible risk' as 'risk less than that run in everyday life'. Now the risks run in every day life are what many people would regard as substantial, both in terms of the lethal and disabling hazards faced and in terms of the probabilities of those hazards being instantiated (this distinction between probabilities and degrees of harmfulness being vital in risk assessment, and often blurred). If everyday risks are to be regarded as the baseline for both, with 'risk less than that run in everyday life' being classified as 'negligible', risks 'questionably greater than negligible' being classified as 'minimal' and anything greater being simply called 'more than minimal', then of course risk of significant morbidity and even mortality can properly be labelled 'negligible' (let alone 'minimal' or 'more than minimal'), for such risk is certainly a part of 'everyday life'. But when in 1973 the RCP moved away from the previous virtually absolute prohibition of NTR on children to acceptance, provided that there was 'negligible risk or discomfort' was that what they meant by 'negligible'? Whether they did or did not, is this degree of risk and greater a morally acceptable basis for NTR on children ? Perhaps it is, but the BPA adduces little argument other than risk benefit considerations to show why it should be so.

The great moral weight placed upon straightforwardly utilitarian risk benefit analysis by the BPA also requires careful consideration. Few would deny (pace Kant) that such analysis is often necessary in medico-moral decision making; but most, on reflection, would deny that it is sufficient. There $\stackrel{\AA}{\varrho}$ must surely be moral curbs upon its exercise, as the $\vec{F}$ BPA implicitly acknowledges when it points out $\overline{\bar{\complement}}$ that no ethical committee would countenance the risk of serious harm 'in any case', presumably even $\stackrel{\vec{\sim}}{\vec{F}}$ if risk benefit analysis indicated that a risk of serious harm for one patient would be accompanied by a 을 truly enormous potential benefit for many others. $\frac{\bar{N}}{\bar{c}}$ These moral curbs can perhaps best be regarded as $\Phi$ aspects of a proper respect for individual persons, including respect for their autonomy. One of the notable features of the BPA guidelines is the $\vec{\circ}$ absence - in contrast with all the other guidelines $\vec{A}$ mentioned - of a specific assertion of the supremacy ${ }^{\omega}$ of the research subject's interests over the interests $\bar{\exists}$ of others. Whether this is accidental or deliberate, ${ }_{\infty}$ the issue requires thorough analysis.

Another aspect of respect for persons and $\vec{\omega}$ autonomy which deserves such analysis is the응 thorny problem of proxy consent. One of the protections still generally available to adult research $\overline{3}$ subjects is that no experiment - certainly no non-therapeutic research - should be done without ${ }^{\supset}$ the subject's informed consent. Many children $\overrightarrow{0}$ however are unable to give informed consent. Is N proxy consent for NTR given by parents on their children's behalf morally acceptable? There are \& strong arguments on both sides of this question and they need to be considered. A further moral problem concerns any children who are able to give $\frac{\mathrm{D}}{\mathrm{C}}$ informed consent. Would informing them truthfully about the intended research be morally acceptable음 if, as research by Schwartz (9) has indicated, understanding such explanations may place an added and severe stress upon the child ?

Finally there is a notable lack in those guidelines which do countenance NTR in children of any:reference to the 'golden rule' (or to its more formal 3 equivalent, the principle of universalisability) either in its positive form - do unto others as you would be 3 done by - or in its negative form - do not do to others what you would not have done to you. In an? important paper on research on children (I0)을 AGM Campbell makes implicit reference to it when he says: 'Though this can be a fallible guide, $N$ the investigator should ask himself as honestly as heN can if this is an experiment to which he would freely N submit his own child if appropriate. Are the risks that small? If he feels hesitant or uncomfortable about this question he should not proceed. His? patients have a right to expect that sort of protection'. Should some form of this principle, be an explicit part of any guidelines on clinical research ?

There are several other moral problems associated $\overrightarrow{\mathbb{D}}$ with research on children. It is to be hoped that the $\frac{?}{\mathbb{1}}$ working party, drawn as it is from a wide range of $\varrho$ disciplines and interests, will produce a moral analysis upon which guidelines for clinical practice 0 may be more clearly based than they are at present. For references see bottom of page $I I$. ํㅡㅁ 
advantage of making it easier to demonstrate openly a proper standard of confidentiality rather than laying responsibility artificially on a particular member of the organisation which is the difficulty created if one follows the logic of the BMA line.

It would not deal entirely with the problem of identifying a third party who works outside the institution, but could make it easier to regulate transmission of information to any external body. Once such a mechanism were established it would be easier to see how some of the more difficult third party issues might be tackled. It is not the aim of this paper to discuss the conflict between confidentiality and issues of wider public interest, but if one accepts the Kennedy (10) argument that many decisions made by doctors require consideration of social values on which they may need guidance, or Thompson's view (II) that there are so many exceptions that the principle of confidentiality is in danger of being eroded out of existence, then custodianship may at least provide a mechanism for dealing with such issues. For example the decision as to whether or not information about a patient should be released to the police would not be made arbitrarily by either the consultant or the administrator. Instead it would have to be decided in the context of the institution's custodianship procedures.

How would such a system be set up ? At health authority level an integrated strategy could be worked out which simultaneously ensured that:

a) professional staff set and review standards of confidentiality to be achieved in given situations, and b) the health authority accepted its responsibilities for maintaining that standard.

The setting of standards requires medical commitment and multi-disciplinary consideration with doctors, nurses and computer experts, and might be assisted by the establishment of a small standing committee, rather like an ethical committee to which problems could be referred and which could if necessary take the initiative itself to take up problems.

The health authority for its part could agree and make public its policies for data protection such as recognition of the need for informed consent of patients to the release of information and clauses in staff contracts which set out their obligations in relation to the handling of patient information. It does this already in other fields and as Health and Safety and Equal Opportunities legislation.

This might at least ensure that future discussions take place within a comprehensible and publicly scrutinised framework.

\section{References}

(I) Confidentiality of medical records - a factless debate. Lancet 1980 Dec 6: 1230.

(2) Report of the Committee on Data Protection (Lindop Report). Cmnd. 7341. London: HMSO, 1978.

(3) See reference (2). Paras 7.11, 18.07.

(4) Annual Report of the Health Service Commissioner 1979-80. London: HMSO, 1980: Chap 5; para $86: 33$.

(5) DHSS Circular (80) I4. Confidentiality of medical records. London: DHSS, 1980.

(6) BMA Central Ethical Committee. Three ethical principles. London: British Medical Association, 1980.

(7) Data protection in health information systems: Considerations and guidelines. North Holland, 1980: II.

(8) Letter from British Medical Association to Members of Parliament, 1978 August 31.

(9) See reference (7) p 22.

(I0) Kennedy I. The Reith Lectures: Unmasking medicine. The Listener 1980 Nov 6, 13, 20, 27, Dec 4, II.

(II) Thompson I E. The nature of confidentiality. fournal of medical ethics $1979 ; 2$ : 57-64.

\section{Continued from page 4}

\section{References}

(I) The Declaration of Helsinki 1964, revised 1975. Reprinted (under 'Declarations') In: Duncan A S, Dunstan G R, Welbourn R B, eds. Dictionary of Medical Ethics. London: Darton, Longman and Todd, r98r.

(2) The Nuremberg Code, 1947. See Dictionary of Medical Ethics, as in reference (I).

(3) Medical Research Council. Annual Report 1962-63. London: HMSO, 1963; Cmd 2382: $21-25$.

(4) Royal College of Physicians. Supervision of the ethics of clinical research investigations in institutions. London, 1973.

(5) DHSS. Supervision of the ethics of clinical research investigations and fetal research. London, 1975; HSC(IS)I53.

(6) Godber Sir G. Constraints on the advance of medicine. Proceedings of the Royal Society of Medicine. 1974; 67: 13II.

(7) BMA. The Handbook of Medical Ethics. London, 1980, revised r981.

(8) British Paediatrics Association. Guidelines to aid ethical committees considering research involving children. Archives of Disease in Childhood 1980; 55: 75-77.

(9) Schwartz A H. Children's concepts of research hospitalisotion. New England fournal of Medicine 1972; 287: 589-592.

(I0) Campbell A G M. Infants, children and informed consent. British Medical fournal r974; 3: 334-338. 